\title{
EFFECT OF FOOT GYM ON SENSE OF FOOT, PARESTHESIA, AND ANKLE BRACHIAL INDEX IN PATIENT WITH TYPE 2 DIABETES MELLITUS
}

\author{
Tavip Dwi Wahyuni \\ School of Health Polytechnic, Malang
}

\begin{abstract}
BACKGROUND: Peripheral arterial disease (PAD) is a complication of diabetes mellitus (DM) type 2 that is often encountered. Peripheral arterial disease is a condition characterized by atherosclerotic occlusive disease of the lower extremities. While $\mathrm{PAD}$ is a major risk factor for lower-extremity amputation, it is also accompanied by a high likelihood for symptomatic cardiovascular and cerebrovascular disease. The PAD can be detected by examination of Ankle-Brachial Index (ABI). Foot gym is an exercise undertaken by patient with DM to prevent foot injury, strengthen small muscle as well as thigh and calf muscles, prevent deformity, and improve joint movement. This study aimed to determine the effect of foot gym on peripheral tissue perfusion in patient with type 2 diabetes mellitus.
\end{abstract}

SUBJECT AND METHODS: This was a quasi-experiment, before and after with no control design, conducted in Pasuruan, East Java. A sample of 40 patients was selected from 68 patients with type $2 \mathrm{DM}$ visiting the Family Doctor Clinic in Grati, Pasuruan, East Java. The dependent variable was peripheral tissue perfusion, consisting of: (1) Sense of foot; (2) Paresthesia; and (3) ABI. The mean score difference in the dependent variables before and after foot gym was tested by Paired t-Test.

RESULTS: Sense of right foot improved from 0.80 before foot gym to 0.70 after foot gym, and it was statistically significant $(p=0.014)$. Sense of left foot improved from 0.75 before foot gym to 0.55 after foot gym, and it was statistically significant $(\mathrm{p}=0.046)$. Paresthesia of right foot decreased from 0.60 before foot gym to 0.50 after foot gym, although it was not statically significant $(\mathrm{p}=0.157)$. Paresthesia of left foot decreased from 0.70 before foot gym to 0.60 after foot gym, although it was not statically significant $(\mathrm{p}=0.480)$. ABI of right foot reduced from 0.98 before foot gym to 0.93 after foot gym, and it was statistically significant $(\mathrm{p}<0.001)$. ABI of left foot reduced from 0.99 before foot gym to 0.95 after foot gym, and it was statistically significant $(\mathrm{p}<0.001)$.

CONCLUSION: Foot gym can improve sense of foot and reduce ABI in patients with diabetes mellitus. This study does not show the effectiveness of foot gym in reducing paresthesia.

Keywords: foot gym, diabetes mellitus, sense of foot, paresthesia, Ankle Brachial Index 